\title{
Ação pedagógica de promoção a crianças e adolescentes institucionalizados: uma face da educação não-escolar
}

\author{
Luzia Borsato Cavagnari ${ }^{1}$
}

\begin{abstract}
RESUMO
$\mathrm{O}$ artigo apresenta um aspecto da atuação de professores e acadêmicos do curso de Pedagogia e outras Licenciaturas no projeto de extensão: Ação Pedagógica de Promoção à Crianças e Adolescentes participantes de Instituições Sociais e Assistenciais de Ponta Grossa. Parte do contexto social e histórico das entidades assistenciais do município e do significado das ações sociais, situando o direito à cidadania como base da formação tanto das crianças/ adolescentes institucionalizadas quanto dos educadores que atuam nas instituições. No texto, as ações de formação dos profissionais são enfatizadas.

Palavras-chave: experiências educacionais não-escolares, educação para a cidadania, formação dos profissionais, promoção de crianças e adolescentes
\end{abstract}

A proposta deste trabalho é apresentar algumas considerações sobre práticas pedagógicas realizadas em instituições não-escolares por professores e acadêmicos do curso de Pedagogia e de Licenciaturas, em uma realidade para a qual o ensino de graduação tem ainda reservado pequenos espaços: o das entidades assistenciais que dão atendimento a crianças e adolescentes destituídos das condições econômicas, culturais, sociais, muitos dos quais em situação de vulnerabilidade.

Experiências educacionais nãoescolares são hoje condição importan-

\footnotetext{
${ }^{1}$ Professora Mestre do Departamento de Métodos e Técnicas de Ensino da UEPG.
} 
te para a formação dos pedagogos e educadores de modo geral. Utilizamos a expressão "não-escolar" para designar as atividades educativas que se desenvolvem em outros espaços que não os "escolares", isto é, na escola formal, estruturada conforme diretrizes das mantenedoras e do sistema educacional. ${ }^{2}$ Ações em prol da promoção de crianças e adolescentes precisam ser conhecidas e praticadas pelos futuros educadores que saem dos cursos de Licenciatura e de Pedagogia. Há que se considerar também a ênfase dada pelas propostas que, no momento atual, vêm redefinindo as diretrizes curriculares para a formação dos educadores, estabelecendo dentre outras capacidades, a da atuação em "unidades e experiências educacionais escolares e não-escolares".

Muito embora as práticas pedagógicas que vêm sendo desenvolvidas no projeto se refiram a diversas situações nas entidades sociais, especialmente no trato com as crianças e adolescentes, optamos no presente estudo por analisar as ações ligadas a um dos aspectos apenas: a formação contínua dos profissionais. A singularidade das instituições referidas não permite, no limite de um texto, aprofundar todos os aspectos, pois que necessitam abordagens e pesquisas mais minunciosas (ou mais detalhadas).

Compreendemos que as práticas educativas ali realizadas não estão prontas, acabadas, mas em processo de constante reflexão, atualização e ação, como possibilidade aliada a um compromisso permanente.

Instituições sociais e assistenciais têm tido grande crescimento no Brasil, crescimento este especialmente ligado ao agravamento das desigualdades e da exclusão social, verificado tanto nos países em desenvolvimento quanto nos países desenvolvidos.

A causa mais recente situa-se no próprio processo de globalização, que não é mais somente da economia ou da informação, mas é também humana. Assim, DELORS explica:

O desenraizamento ligado às migrações e ao êxodo rural, o desmembramento das famílias, a urbanização desordenada, a ruptura das solidariedades tradicionais de vizinhança, lançam muitos grupos e individuos no isolamento e na marginalização (...) (1998, p.52-53).

\footnotetext{
${ }^{2}$ GOHN utiliza a expressão educação não-formal, processo de educação onde existe "intencionalidade de dados sujeitos em criar ou buscar determinadas qualidades e/ou objetivos" (1999, p.100). No seu estudo, a autora distingue seis áreas de abrangência de educação nãoformal. Identificamos, nas atividades por nós realizadas, aquelas que a autora define como "aprendizagem dos conteúdos da escolarização formal, escolar, em formas e espaços diferenciados. Aqui, o ato de ensinar se realiza de forma mais espontânea, e as forças sociais mais organizadas de uma comunidade têm o poder de interferir na delimitação do conteúdo didático ministrado, bem como estabelecer as finalidades a que se destinam aquelas práticas (op. cit. p.99)
} 
No caso específico de Ponta Grossa, até dezembro de 1996, existiam 73 entidades assistenciais cadastradas nos Conselhos e 16 entidades mantenedoras, sendo 5 estatais e 68 filantrópicas. Dessas entidades, $45,2 \%$ foram constituídas nas décadas de 80 e $90,39,7 \%$ dos anos 50 até fins dos anos 70 e 8,2\% foram fundadas entre o início do século até fins dos anos 40, como o Asilo São Vicente de Paulo (1916) e a Sociedade Espírita Francisco de Assis de Amparo aos Necessitados (1912). ${ }^{3}$

A cidade de Ponta Grossa possui, portanto, tradição de caridade e filantropia, que está presente na sua história consubstanciada não apenas nas entidades assistenciais sem fins lucrativos, fundamentadas em princípios doutrinários e de solidariedade, como nas associações beneficentes ligadas aos clubes sociais alemães, fundadas em 1896 (Clube Germânia, atual Clube Guaíra) e 1897 (Sociedade Beneficente Germânia, atual Clube Verde). É significativo observar que esta última, na sua fundação, tinha como "finalidade principal auxiliar os associados, em casos de doenças e de falecimento, através da criação de uma Caixa Beneficente com fundo disponível provindos da contribuição dos associados para as situações" (BATISTA, 1998, p.41).

Consideramos que a beneficência característica comum a quase todas as sociedades alemãs fundadas no sul do Brasil (LAVALLE, 1996, p.55) também se efetivam na cidade, motivado pela necessidade de ajuda mútua dos imigrantes.

Essa característica marcou também o trabalho de um grupo de senhoras que constituíram, em 14 de março de 1902, a Associação das Damas da Caridade, sobre a qual afirma LAVALLE:

sua principal atuação, entre 1902 a 1908, foi a de arrecadar fundos para dar assistência médica, fornecer remédios, alimentos e roupas aos doentes carentes da cidade. Para isso contavam com um número de associadas contribuintes, além de obterem da comunidade recursos extras que lhes permitam a distribuição de algum conforto aos pobres. Esse viver o dia-a-dia dos indigentes levou essas senhoras a assumirem, em 1908, a liderança dos trabalhos pró-construção da Santa Casa (1996, p.111).

A expressão "Ponta Grossa: capital da caridade" é assim justificada, sendo largamente empregada por políticos e profissionais quando à cidade se referem ou quando apelam para a solidariedade do seu povo.

Constatamos, portanto, num retrospecto da história local, que as

${ }^{3}$ Os dados utilizados foram tomados da pesquisa de BOURGUIGNON, 1997. 
entidades assistenciais sem fins lucrativos ocupam lugar significativo no município e são alicerçadas em conceitos como caridade, filantropia, beneficência. A caridade fundamenta-se no vocabulário cristão que, segundo FERREIRA, significa "o amor que move a vontade à busca efetiva do bem de outrem e procura identificar-se com o amor de Deus" (1986, p. 353).

A filantropia é para NÉRY respaldada na

idéia do trabalho enquanto fonte de riqueza, o qual demandava um controle sobre o bem-estar dos indivíduos pobres, considerados a força de trabalho por excelência. A noção de assistência se amplia e evolui aliada ao não desperdício das 'forças vivas', ou seja, a filantropia passa a assumir o encargo de assistir os pobres não produtivos, garantindo a estes as condições para trabalharem nas manufaturas da época e não mais confiná-los em casas de caridade. Na medida em que o grande contingente de mendigos não trabalhadores vai sendo substituido pelo contingente de operários pobres e carentes, a reflexão em termos de pobreza passa do âmbito da moral religiosa para os moldes políticos e econômicos (apud BOURGUIGNON, 1997, p.32-33).

Vê-se, desta forma, a laicização do termo caridade, uma evolução do caráter da assistência, assim analisada por BOURGUIGNON: "a filantro- pia, ascende como alternativa de enfrentamento das seqüelas sociais, a partir do século XIX e dá um caráter renovado à caridade, agora praticada com bases racionais" (ibidem, p. 33).

Com a instalação dos governos democráticos e a luta pela igualdade de direitos, a assistência social passa mais e mais a ser assumida pelo Estado para garantir a cidadania, conservando-se, no entanto, as entidades privadas ou sociedades sem fins lucrativos, mantidas e administradas por cidadãos e subvencionadas por recursos públicos.

A cidadania é, pois, um conceito em expansão, condição reconhecida a todas as pessoas e, no que concerne à criança e ao adolescente, a Constituição Federal de 1988 estabelece no artigo 227:

É dever da familia, da sociedade e do Estado assegurar à criança e ao adolescente com absoluta prioridade, o direito à vida, à saúde, à alimentação, à educação, ao lazer, à profissionalização, à cultura, à dignidade, ao respeito, à liberdade e à convivência familiar e comunitária, além de colo-cálos a salvo de toda forma de negligência, discriminação, exploração, violência, crueldade e opressão (BRASIL, 1988, p.52).

Com o reconhecimento dos direitos sociais, institucionalizam-se no Brasil o Estatuto da Criança e do Adolescente (13/07/1990) e a Lei Orgânica de Assistência Social (Lei $\left.n^{\circ} 8742 / 93\right)$ instrumentos importantes 
para a concretização dos ideais de proteção, bem como da promoção das crianças e adolescentes destituídos das suas condições básicas, universo no qual situa-se como objetivo maior o projeto por nós coordenado.

O projeto insere-se, por conseguinte, no âmbito das 28 entidades que prestam assistência às crianças e adolescentes ( 4 estatais e 24 privadas) do conjunto de 73 entidades assistenciais existentes em Ponta Grossa.

O direito à cidadania é hoje proclamado pela legislação, porém pouco praticado na maioria das instâncias governamentais e privadas. É preciso, assim, educar para a cidadania, em primeiro lugar, distinguindo cidadania ativa de cidadania passiva. Esta é, para BENEVIDES,

outorgada pelo Estado, com a idéia moral da tutela e do favor", enquanto cidadania ativa é "aquela que institui o cidadão como portador de direitos e deveres, mas essencialmente criador de direitos para abrir espaços de participação (1998, p.169).

Entendemos, assim, que o envolvimento da Universidade por meio dos professores e acadêmicos estagiários precisa promover a educação para a cidadania ativa, visando a superar os conceitos de caridade, filantropia e assistencialismo. Dessa forma, a instituição estará formando pessoas para participarem de diferentes processos sociais, conscientes de seus direitos, mas também dos seus deveres.

Com essa concepção e acreditando na articulação da extensão com o ensino e a pesquisa, temos encaminhado as atividades. As duas instituições campo das atividades desenvolvidas pelo projeto, fazem parte, segundo sua origem, mantenedora e filosofia, do grupo de entidades privadas (das 24 que prestam assistência às crianças e adolescentes no município), filantrópicas e sem fins lucrativos mantidas e administradas por associações e subvencionadas parcialmente por recursos públicos.

As entidades recebem crianças e adolescentes cujas famílias são extremamente carentes de valores culturais, relações familiares e bens materiais. Os pais (quando têm) não possuem emprego fixo: são operários, bóias-frias, diaristas, e as mães fazem serviços de limpeza e outros trabalhos não qualificados. Há também aqueles pais que são desempregados.

Evidentemente, essas carências trazem, em conseqüência, muitos problemas evidenciados pelo comportamento das crianças e especialmente das meninas, pois muitas são abandonadas pelas famílias e/ou exploradas, sofrem violência por parte dos pais, em função do alcoolismo e de outras drogas. Por isso, são assistidas em regime de abrigo e de liberdade acompanhada, encaminhadas pelo Conselho Tutelar da Criança e do Adolescente.

Em pesquisa realizada com jovens de uma das instituições, que abriga somente meninas, MARTINS carac- 
terizou a realidade:

O espaço geográfico desse grupo investigado é circunscrito pelos limites do próprio bairro ou da favela, assim como os seus relacionamentos sociais e amorosos, vez que raramente as encontramos nas ruas centrais da cidade. Ao desafiar-nos com seu comportamento agressivo e valores diferentes, denunciam uma sociedade perplexa diante dos graves problemas que gerou (1994, p.32).

Essa é, pois, uma situação que se faz cada vez mais presente na sociedade globalizada em que vivemos, formada por um número acentuado de excluídos e marginalizados em todos os sentidos, que são também pessoas merecedoras de uma educação cidadã. Assim, crianças e adolescentes socialmente desprivilegiados estão nas salas de aula, são os alunos reais que temos e não os que idealizamos; portanto, precisam ser conhecidos dos acadêmicos, futuros professores e supervisores.

Nesse contexto, destaca-se a importância da conjugação de estudos sobre os fundamentos teóricos da educação e os fundamentos político-pedagógicos necessários ao entendimento e desvelamento da problemática do menor carente.

Embora seja muitas vezes conhecida dos acadêmicos a realidade vivida por essas crianças e adolescentes que também (mas nem sempre) estão nas escolas, ela não se apresenta na sua verdadeira face - nua e crua, como a que identificamos quando do contato com as mesmas nas instituições sociais. Esse quadro é visualizado de maneira mais forte ainda na entidade que mantém grupo de meninas internas.

Logo, a participação dos estagiários em instituições não-escolares se afigura como de extrema relevância, uma vez que se torna possível perceber com maior clareza as carências demonstradas pelas crianças e adolescentes, bem como estabelecer relações com o comportamento que elas manifestam na escola.

Conhecida a realidade das crianças e adolescentes, das instituições e dos recursos humanos que nelas trabalham, os estagiários juntamente com os professores e supervisores da Universidade e coordenadores das instituições levantam as necessidades, que são selecionadas e priorizadas.

O encaminhamento e orientação das ações se faz com base em um processo reflexivo e de estudo teórico, a partir da constituição de um clima de confiança e de trabalho coletivo.

Das atividades que têm sido realizadas, destacam-se projetos de revisão de conteúdos curriculares e/ou complementação de estudos com as crianças e adolescentes em dificuldades de aprendizagem; formação humana, visando à orientação e ao resgate de valores e da auto-estima; oficinas de leitura, produção de textos formação do leitor-escritor; oficinas 
de teatro, música, dança; excursões; mini-cursos.

Em um momento da execução do projeto, uma das instituições manifestou a expectativa de que algumas das ações com as crianças e adolescentes fossem realizadas por nós, professores, ou por convidados.

Procuramos, então, a partir de base teórica, esclarecer a finalidade do projeto de extensão, priorizando a participação dos acadêmicos - estagiários, supervisionados por seus professores orientadores. Salientamos, também, que convidar outros profissionais não identificados com a filosofia e problemática da Instituição não se revela eficaz, uma vez que, atuando de fora, nem sempre eles se vêem comprometidos com o processo e oas decorrentes encaminhamentos, que ficam para ser resolvidos pelos profissionais que pertencem ao quadro institucional.

Consideramos que as dificuldades vividas na realidade da Instituição devem ser discutidas pelos seus protagonistas, juntamente com a equipe dirigente e os demais envolvidos no projeto. A partir daí, os encaminhamentos far-se-ão com quem convive com os jovens diariamente e têm poder, competência e compromisso com a transformação e com o projeto que por eles foi discutido.

Partimos, portanto, da ação supervisora compartilhada, com base em um dos pressupostos apontados por FALCÃO FILHO: "A ação supervisora deve ser desenvolvida com os professores e não para os professores" (1986, p. 4). Logo não se admitem mais decisões tomadas centralizadamente para serem cumpridas sem discussão pelos mais interessados: os professores - agentes do processo.

Nesse sentido, argumentamos com à direção, que palestras realizadas por especialistas têm a sua importância para a atualização, reflexão, questionamentos de quem vê o espaço da Instituição de fora, e assim pode contribuir com ela. Mas é preciso também, e principalmente, formar os profissionais que nela atuam, pois são eles que permanecem e, assim, possuem (ou devem possuir) maior compromisso com as crianças/jovens ali formados.

Refletimos com a equipe sobre a sua ação no sentido de promover nos adolescentes a consciência do sentido e do significado da presença que eles têm na Instituição, ficando claro que ali é lugar de formação para a cidadania, para promoção de valores, habilidades e preparação para a vida. Por isso, a proposta educacional deve ser construída com e pelos professores, que por sua vez precisam tornála explícita para os alunos e com eles buscar a sua concretização, pois só se alcançam os objetivos perseguidos pelo trabalho coletivo, no qual toda a equipe, juntamente com as crianças e adolescentes, sintam-se felizes e coresponsáveis tanto por seus sucessos como por seus fracassos.

Para a efetivação das ações de formação de professores e/ou atendentes 
é preciso contar tanto com a capacidade de organização da instituição, quanto com os professores de estágio da Universidade. Nesta, a interação entre os docentes e discentes resulta em parcerias, fazendo com que, enquanto um grupo de acadêmicos realiza a formação de professores/ atendentes, outro esteja em sala de aula com as crianças/adolescentes. Isso se dá porque buscamos a formação de todos: professores, atendentes e equipe de direção, pois entendemos que não há projeto político-pedagógico que se sustente sem a formação continuada de todos os profissionais que atuam em uma instituição.

Consideramos que uma instituição, ao perseguir objetivos necessita do compromisso de todos os envolvidos no processo, os quais precisam sentirse responsáveis pelo sucesso ou não do empreendimento. Por isso, ao mesmo tempo em que se realiza grupo de estudos com a equipe se faz o acompanhamento dos professores/ atendentes (muitos deles sem possuir formação inicial básica) em sala de aula, pela observação, participação nos trabalhos, demonstrações, a fim de darlhes suporte e ajudá-los a refletir sobre o seu trabalho e aperfeiçoá-lo.

Essa é a função primeira da atuação supervisora, seu objeto de trabalho, uma luz que conforme MEDINA:

O papel do supervisor passa, (...) a ser redefinido com base em seu objeto de trabalho, e o resultado da relação que ocorre entre o pro- fessor que ensina e o aluno que aprende passa a se constituir o núcleo do trabalho do supervisor na escola. A forma fácil ou difícil usada pelo professor para que o aluno aprenda, será, portanto, o foco da pesquisa, do estudo e da reflexão por onde flui o trabalho do supervisor (1997, p.22).

Muito embora não se trate de educação escolar, as entidades precisam oferecer um ambiente educativo, pedagógico e de construção da cidadania. Assim, de nada adianta introduzir inovações na legislação sobre o menor carente, se não se investir na formação dos profissionais que com ele atuam e que, portanto, nele exercem profundas influências. Mesmo que bem intencionados, tais profissionais nem sempre são portadores das condições e preparo para o exercício das funções pedagógicas bem como de orientação e aconselhamento que lhes são exigidas no trato com crianças e adolescentes.

Resultados concretos das intervenções realizadas até o momento já se verificam. Hoje, existe por parte das professoras/atendentes maior consciência das funções por elas desempenhadas; percebem a relação da teoria, a partir do estabelecimento de princípios e objetivos para as ações práticas. Segundo a Coordenadora, foram retomadas reuniões de planejamento, embora com resistência, no início, de algumas professoras/ atendentes, porém aceitas e deseja- 
das agora pelo grupo. Percebemos o crescimento dessas profissionais nas reuniões e no cotidiano da sala de aula, pelo interesse por elas demonstrado em relação ao estudo teórico, pela sua busca de maior conhecimento e pela aplicação das propostas construídas com elas no processo de formação. Importante é destacar que o projeto tem continuidade e que as ações desencadeadas são sempre retomadas, avaliadas, atualizadas, pela inserção de novos grupos de estagiários que conferem mais vida e movimento ao trabalho docente e discente.

Assim, o direito à cidadania precisa assistir não só às crianças/adolescentes, como sobretudo aos educadores, muitas vezes destituídos também das condições para a plena realização de suas funções e das finalidades institucionais.

\section{REFERENNCIAS BIBLIOGRÁFICAS}

1 BATISTA, Maristela Yurk. Clube Princesa dos Campos - 1897/ 1997: 100 anos de beneficência, conquista e realizações na sociedade ponta-grossense. Ponta Grossa: Inpag, 1998

2 BENEVIDES, Maria Vitória de Mesquita. Educação para a cidadania e em direitos humanos. Anais do IX Encontro Nacional de Didática e Prática de Ensino. Águas de Lindóia, v.1/
1, maio/1998. p.165-177.

3 BOURGUIGNON, Jussara Ayres. $O$ processo de configuração da assistência social no município de Ponta Grossa - PR. São Paulo, 1997. Dissertação de mestrado. PUC/SP.

4 BRASIL. Constituição da República Federativa do Brasil. São Paulo : Editora Tecnoprint, 1988.

5 CAVAGNARI, Luzia Borsato. Relatório parcial do Projeto de Extensão: Ação Pedagógica de Promoção às Crianças e Adolescentes participantes de Instituições Sociais e Assistenciais de Ponta Grossa. Ponta Grossa: UEPG, mar. 1999.

6 DELORS, Jacques. Educação: um tesouro a descobrir. São Paulo: Cortez, Brasília: MEC, UNESCO, 1998. 287p.

7 FALCÃO FILHO, José Leão. Uma supervisão compartilhada: a relação professor-supervisor. AMAE Educando. Belo Horizonte, maio/1986. p.4-12.

8 GOHN, Maria da Glória. Educação não-formal e cultura política: impactos sobre o associativismo do terceiro setor. São Paulo : Cortez, 1999.

9 LAVALLE, Aída Mansani. Germânia Guaíra: um século de sociedade na memória de Ponta Grossa. Ponta Grossa: Centro de Publicações, 1996. 320 p. 
10 MARTINS, Maria José Bastos. As meninas mesmo à margem têm voz e falam sobre a escola. Guarapuava, 1994. Dissertação de mestrado. Universidade Estadual de Campinas/Universidade Estadual do Centro-Oeste do Paraná.

11 MEDINA, Antonia da Silva. Supervisor escolar: parceiro político-pedagógico do professor. SILVA JR, Celestino Alves da; RANGEL, Mary. (Orgs) Nove olhares sobre a supervisão. Campinas : Papirus, 1997. p.9-35. 